\title{
EDITORIAL
}

\section{The Case Report: Clutter or Contribution to Medical Literature?}

The single case report always poses a difficult decision for the editors of a journal. Publication of a case report elevates a personal experience, curious coincidence, or problematic patient from the anecdotal informality of bedside rounds to the documented authority of a referred journal. The case may launch the academic career of an aspiring resident, teach the inexperienced writer to research the literature on a limited topic, or provide the experienced writer with an expanded curriculum vitae that solicits the respect of colleagues and ensures academic promotion. For the journal editor, however, the question arises even if a paper is interesting and well written: Is it deserving of publication and of biomedical indexing for all time?

There is no doubt that some major contributions to medical knowledge have been heralded by a case report. A few examples may be cited from the disciplines of neurology, neurosurgery, and neuropathology. The association of thymoma excision with remission in myasthenia gravis was first described in a case report of a 19-year-old woman by Blalock et al in 1939.' Ironically, this patient remains the youngest in the literature to date with this combination of diseases, although the association has been confirmed many times in young and middle-aged adults. Victor Hardy published a case report in 1886 of successful surgical treatment of post-traumatic epilepsy in a 16-year-old boy, by resection of a left Rolandic focus, ${ }^{2}$ providing the pioneering effort for modern epilepsy surgery. Malignant hyperthermia and its hereditary character was first described as a letter-to-theeditor by Denborough et al in $1960 .^{3}$ Many anaesthetic deaths from this necrotizing myopathy have subsequently been prevented by this case report that inspired closer scrutiny by these and other authors. Phenytoin, a then recently introduced anticonvulsant, was first discovered to be effective in treating trigeminal neuralgia by Bergouignan in 1942, who published a case report of a woman who suffered from both tic douloureux and epilepsy. ${ }^{4}$ Luft et al. described a mitochondrial myopathy in one woman. ${ }^{5}$ Though the hypermetabolism manifested in this single case remains rare, this report led to recognition of a whole spectrum of mitochondrial diseases affecting brain and muscle. Alzheimer's 1907 case report of the histopathological findings in the brain of a demented 51-year-old woman is now a classic in neuropathology. ${ }^{6}$

The reverse side of the coin is that some authors of case reports have become immortalized by their lack of insight. Other case reports merely achieve a status of medical irrelevance. The 14-year-old girl described by Schilder in $1912,{ }^{7}$ has neither the neuropathological nor the genetic features of adrenoleukodystrophy, the most common pathology found in more recently reported cases of "Schilder's disease". His second case, reported in $1913,{ }^{8}$ is now recognized as metachromatic leukodystrophy. In 1900 Oppenheim described infantile hypotonia as a disease that became known as "amyotonia congenita" or "Oppenheim's disease". ${ }^{9}$ Oppenheim concluded that it was a benign and reversible condition because such severe hypotonia was never seen in adult life. For a time his eponym became an alternative appellation for spinal muscular atrophy (hardly a benign disease) but it soon became obsolete because it was so devoid of meaning. Contemporary terms almost certainly destined for a similar fate include "senile dementia" and "benign congenital hypotonia". Most diagnostic fantasies do not achieve notoriety, immortality in infamy, or even modest ridicule. They are simply forgotten, passively by kind colleagues of the author, and actively by editors of the journal in which they are published.

What, then, should be the criteria applied by editors of medical journals to submitted manuscripts that describe single or even two or more patients with unusual findings? Nothing provokes an editorial yawn more readily than the all too common manuscript beginning with a statement - "The world literature contains only 27 recorded cases of this rare condition. We report here a 28th case." How many patients are required to elevate the case report to a "series" or "study"? Both editors and potential authors need guidelines to separate the scientifically useful case report from "interesting" but useless trivia that clutter the ever-expanding literature.

The following four criteria are suggested as such a guide to potentially useful case reports: (1) Does the case offer insight into the etiology or pathogenesis of a disease? (2) Does the case provide positive (or negative) evidence of a new or unproved treatment that may benefit (or harm) patients? (3) Does the case describe an unrecognized association of two or more diseases that is more than random coincidence? (4) Does the case describe a new disease not previously recognized, or confirm a previous case report of this disease? The number of confirmations needed to establish a recurring condition without being redundant is a difficult editorial decision.

If one reexamines the case reports that time has proved to be of major importance in understanding disease, including the few examples cited above, one finds that all have fulfilled one or more of these four criteria. There remains a definite place for the case report in this journal. But those cases that do not meet these criteria, however "interesting" or "well worked up" that they may be, are better suited to Hospital Grand Rounds.

\section{Harvey B. Sarnat \\ Associate Editor}

Robert G. Lee

Editor-in-Chief

\section{REFERENCES}

1. Blalock A, Mason MF, Morgan HF, et al. Myasthenia gravis and tumors of the thymic region. Ann Surg 1939; 110:544-561.

2. Horsley VAH. Brain surgery. Br Med J 1886; 2: 670-675. 
3. Denborough MA, Lovell RRH. Anaesthetic deaths in a family. Lancet 1960; 2: 45 (letter).

4. Bergouignan M. Rev Laryngol (Paris). 1942; 63: 34.

5. Luft R. Ikkos D, Palmieri G, Ernster L, et al. A case of severe hypermetabolism of non-thyroid origin with a defect in the maintenance of mitochondrial respiratory control: a correlated clinical, biochemical and morphological study. J Clin Invest 1962; 41: 1776-1804.

6. Alzheimer A. Ueber eine eigenartige Erkrankung der Hirnrinde. Allegmeine Z Psychiatr 1907; 64: 146-148.
7. Schilder P. Zur Kenntniss der sogenannten diffusen Sklerose. (Über Encephalitis periaxialis diffusa) $\mathrm{Z}$ ges Neurol Psychiatr 1912; 10: 1-60.

8. Schilder P. Zur Frage der Encephalitis periaxialis diffusa (sogenannte diffuse Sklerose). Z ges Neurol Psychiatr 1913; 15: 359-376.

9. Oppenheim $\mathrm{H}$. Über allgemeine und localisierte Atonie der Muskulatur (Myatonie) in Frühen Kindersalter. Mschr Psychiatr Neurol 1900; 8: 232-233. 